\title{
Is dairy product consumption associated with the incidence of $\mathrm{CHD}$ ?
}

\author{
Elisea E Avalos, Elizabeth Barrett-Connor, Donna Kritz-Silverstein, Deborah L Wingard, \\ Jaclyn N Bergstrom and Wael K Al-Delaimy* \\ Department of Family \& Preventive Medicine, University of California, 9500 Gilman Drive \#0628, La Jolla, \\ San Diego, CA 92093-0628, USA
}

Submitted 23 February 2012: Final revision received 23 June 2012: Accepted 1 August 2012: First published online 2 October 2012

\begin{abstract}
Objective: Studies examining the association of dairy consumption with incident CHD have yielded inconsistent results. The current prospective study examined the association between dairy consumption and CHD in a population-based sample of older community-dwelling adults.

Design: Baseline CHD risk factors were assessed and an FFQ was self-administered. Participants were followed for morbidity and mortality with periodic clinic visits and annual mailed questionnaires for an average of $16 \cdot 2$ years, with a $96 \%$ follow-up rate for fatal and non-fatal CHD.

Setting: Community.

Subjects: Participants were 751 men and 1008 women aged 50-93 years who attended a clinic visit in 1984-1987.

Results: At baseline the mean age was 70.6 (SD 9.8) years for men and $70 \cdot 1$ (SD 9.3) years for women. Participants who developed CHD during follow-up were significantly older $(P<0 \cdot 001)$, had higher BMI $(P=0 \cdot 035)$ and higher total cholesterol $(P=0 \cdot 050)$, and were more likely to be male $(P<0 \cdot 001)$, diabetic $(P=0 \cdot 011)$ and hypertensive $(P<0 \cdot 001)$, than those who did not develop CHD. Multivariate regression analyses adjusting for age, BMI, diabetes, hypertension, LDL-cholesterol and oestrogen use (in women) indicated that women who consumed low-fat cheese 'sometimes/often' and women who consumed non-fat milk 'sometimes/often' had an increased risk of incident CHD (hazard ratio $=2 \cdot 32$; $95 \%$ CI $1 \cdot 57,3 \cdot 41$ ) and CHD (hazard ratio $=1 \cdot 48 ; 95 \%$ CI 1·02, 2・16) compared with women who 'never/rarely' ate these dairy products.

Conclusions: Woman with higher intake of low-fat cheese and non-fat milk seem to have a higher risk of incident CHD. This needs further investigation considering recent evidence of cardiovascular benefits from certain dairy fat.
\end{abstract}

Keywords

CHD

CHD risk factors Dairy consumption
Milk consumption has been considered a risk factor for atherosclerosis and CHD due to its relatively high cholesterol, SFA and lactose content ${ }^{(1)}$. However, many studies examining the association of milk products with CHD have yielded inconsistent results ${ }^{(2-41)}$. Concern about an adverse effect of milk consumption on vascular disease risk is supported by reports showing that diets high in cholesterol and saturated fat increase the risk for $\mathrm{CVD}^{(2-5)}$. However, more recent studies indicate that Ca and protein in dairy products may be associated with reduced blood pressure and risk of stroke ${ }^{(42,43)}$. The Dietary Approaches to Stop Hypertension (DASH) study has shown substantial blood pressure reductions achieved by simply adding low-fat dairy products to a healthy food and vegetable diet ${ }^{(44)}$. Furthermore, studies have suggested that dairy or Ca contributes to maintaining a healthy body weight ${ }^{(45)}$.
Hu et al. reported that consumption of high-fat dairy products in the Nurses' Health Study was associated with an increase in CHD risk ${ }^{(6)}$. With the exception of the Nurses' Health Study, however, most cohort studies do not support an association between dairy consumption and increased risk for CHD and suggest, instead, that dairy products may help prevent $\mathrm{CHD}^{(10-13,30,33-35)}$. In a meta-analysis of twenty studies on milk or dairy consumption and incidence of vascular disease conducted in 2008 , Elwood et al. reported a reduction of $10-15 \%$ in the incidence of heart disease in the men and women who reported drinking the most milk ${ }^{(14)}$. However, a more recent meta-analysis (2011) of prospective cohort studies found no consistent association between milk and CHD risk $^{(15)}$. The evidence for and against milk and CHD risk was also debated in a series of commentaries which concluded that there was no clear support for a harmful 
or protective effect of milk on $\mathrm{CHD}^{(16,17)}$. The Collaborative Study, a prospective cohort study, conducted in an era when most people consumed full-fat milk, found no evidence that men who consumed milk each day were at increased risk of death from all causes or $\mathrm{CHD}^{(18)}$. More recently, three cohort studies have found that individuals who consumed low-fat dairy compared with high-fat dairy were less likely to develop $\mathrm{CHD}^{(29,40,41)}$.

The purpose of the present study was to examine the association of dairy product consumption (milk, non-fat milk, cream, ice cream, yoghurt, cheese, low-fat cheese, cream cheese, cottage cheese, butter, hot chocolate and milk chocolate) with CHD in a well-characterized cohort of men and women who provided detailed information on diet at a time before milk and dairy restrictions were commonly recommended, and who were followed for up to 20 years for CHD morbidity and mortality.

\section{Experimental methods}

Between 1972 and 1974, 82\% of all adult residents of a southern California community, Rancho Bernardo, participated in a study of heart disease risk factors. All were Caucasian, middle class and community dwelling. They have been followed since initial enrolment with periodic clinic visits and annual mailed questionnaires. Between 1984 and 1987, 82\% of local survivors ( $n$ 2837) aged 40 years or older at baseline participated in a follow-up clinic visit. After excluding eighty-nine participants less than 50 years of age at baseline, four using aspirin, thirtythree premenopausal women, 115 with C-reactive protein $>10 \mathrm{mg} / \mathrm{l}$ and 498 who had known CHD, there remained 751 men and 1008 postmenopausal women who form the basis of the present report. The study was conducted according to the guidelines laid down in the Declaration of Helsinki and all procedures involving human subjects were approved by the University of California, San Diego Human Research Protections Program. Written consent was obtained from all individuals prior to participation.

\section{Procedures}

During the 1984-1987 visits a standardized interview was used to obtain medical history and information on lifestyle variables including: alcohol consumption (number of drinks per week), smoking (never/past/current) and exercise three or more times per week (no/yes). Information on dairy and other food intake was obtained using a 128-item self-administered FFQ that contained questions regarding portion size and consumption frequency (never, 1-11 times/year, 1-3 times/ month, 1-3 times/week, 4-6 times/week and daily) of common food items, including, but not limited to: milk, non-fat milk, cream, ice cream, yoghurt, cheese, low-fat cheese, cream cheese, cottage cheese, butter, hot chocolate and milk chocolate.
Blood samples were obtained by venepuncture between 07.00 and 11.00 hours after a requested fast for $12-16 \mathrm{~h}$. Serum and plasma were separated and stored at $-70^{\circ} \mathrm{C}$ until they were analysed for blood lipids and $\mathrm{C}$-reactive protein. Height and weight were measured with participants wearing light clothing and no shoes. BMI, calculated as weight (in kilograms) divided by the square of height (in metres), was used as an estimate of obesity. Systolic blood pressure and diastolic blood pressure were measured by a nurse trained in the Hypertension Detection and Follow-up Program Protocol ${ }^{(46)}$ after the participant had been seated quietly for $5 \mathrm{~min}$; the average of two measurements was used. Current medication use was validated with prescriptions and containers brought to the clinic for that purpose.

Lipids and lipoproteins were assayed using fresh plasma in a Lipid Research Clinics laboratory at the University of California, San Diego (San Diego, CA, USA). Total cholesterol and TAG levels were measured by enzymatic techniques using an ABA-200 biochromatic analyser (Abbott Laboratories, Irving, TX, USA). HDLcholesterol was measured by precipitating other circulating lipoproteins with heparin and manganese chloride according to the standard Lipid Research Clinics proto$\mathrm{Col}^{(47)}$. LDL-cholesterol was estimated using the Friedewald formula $^{(48)}$. Plasma glucose levels were measured by the glucose oxidase method.

Medical history and incident CHD information were obtained using standard questionnaires at research clinic visits approximately every 4 years thereafter and from annual mailed surveys. Follow-up continued over 20 years through 2007. Death certificates were obtained for $90 \%$ of all decedents and coded by a certified nosologist using the International Classification of Diseases 9th revision (ICD-9) criteria; decedents whose death certificates were not yet available were excluded from this analysis.

\section{Statistical analysis}

Prevalent CHD was defined as doctor-diagnosed myocardial infarction, angina or coronary artery bypass grafting in 1984-1987. Study participants were classified as incident CHD cases if any time during the follow-up period they had a fatal or non-fatal myocardial infarction, coronary artery bypass grafting or angina (grades 1 or 2 by Rose criteria $)^{(49)}$. Myocardial infarction was diagnosed based on self-reported history of physician-diagnosed myocardial infarction. Vital status was known for $96 \%$ of participants. Fatal CHD included deaths assigned ICD-9 codes 410-414. Participants who were alive and event-free were censored at the end of follow-up (31 December 2007) or at the date of their last follow-up for the $4 \%$ for whom vital status was unknown. Individuals who died of nonCHD causes were censored at time of death.

To achieve greater statistical power, we collapsed dairy intake categories into two categories: 'never/rarely' (defined as 0-11 times/year) and 'sometimes/often' 
(defined as 1-3 times/month, 1-3 times/week, 4-6 times/ week and daily). Alcohol consumption was not normally distributed and was log transformed for analysis. Age was examined as a continuous variable and also categorically by decade (50-59, 60-69, 70-79 and 80-89 years). Hypertension was defined as systolic blood pressure $\geq 130 \mathrm{mmHg}$ or diastolic blood pressure $\geq 85 \mathrm{mmHg}$ or use of antihypertensive medication ${ }^{(50)}$. Type 2 diabetes was defined using the 1999 WHO diabetes criteria, defined as fasting plasma glucose $\geq 126 \mathrm{mg} / \mathrm{dl}$, post-challenge glucose $\geq 200 \mathrm{mg} / \mathrm{dl}$, a history of diabetes diagnosed by a physician or use of diabetes-specific medication ${ }^{(51,52)}$.

Means and rates were calculated for continuous and categorical demographic and dairy variables. Comparisons of individuals with and without incident CHD were performed with $t$ tests and $\chi^{2}$ analyses for continuous and categorical variables, respectively. Age-adjusted comparisons of those with and without incident CHD on demographic and lifestyle variables, death outcome and dairy consumption were performed. Exploratory model analyses were completed to assess multicollinearity, and then simultaneous regression analyses were performed to examine the association between each dairy product with incident CHD after adjusting for potentially confounding covariates. Stratified analyses and interaction terms were included to examine the sex-specific association between dairy consumption and incident CHD. No significant interactions were found between dairy consumption and sex; however, sex-specific analyses are presented for incident CHD to allow comparisons with results of other studies.

Multivariate Cox regression models were used to examine the association between consumption of each dairy product and incident CHD. All models met the proportional hazards assumption; none of the regression results were significantly influenced by outliers. The proportionality assumption for significant factors was tested graphically and by including time-dependent covariates in the model. Follow-up duration was calculated from date of research clinic visit until death, outcome, loss to follow-up or 31 December 2007, whichever came first. Results were expressed as hazard ratios (HR) with 95\% confidence intervals. Unadjusted univariate associations of each covariate as predictors of CHD events were examined and included as covariates in later models. Model 1 adjusted for age and BMI; model 2 adjusted for age, BMI, diabetes, hypertension, LDL-cholesterol and current oestrogen use in women. All $P$ values are two-sided; $P \leq 0.05$ was considered statistically significant. All data manipulation and analyses were conducted using the SAS statistical software package version $9 \cdot 1 \cdot 3$ (2006).

\section{Results}

As shown in Table 1, average age of participants was $70 \cdot 6$ (SD 9.8) years in men and 70.1 (SD 9.3) years in women. In the total population, few participants were current smokers (13\%) and $82 \%$ of participants reported physical exercise, usually walking, three or more times weekly; hypertension was common (71\%) and $40 \%$ of women were currently using oestrogen therapy. Of the 1759 older adults included in the study, 451 (222 men and 229 women) reported their first CHD event during the 20 years of followup. Table 1 also shows the proportion of men and women who reported 'never/rarely' or 'sometimes/often' consuming the following dairy products: cheese, ice cream, milk chocolate, butter, cream, non-fat milk, yoghurt, cream cheese, cottage cheese, hot cocoa and low-fat cheese. Cheese consumption was reported as 'sometimes/often' consumed by $92 \%$ and $90 \%$ of men and women, respectively. Ice cream, whole milk and cottage cheese were reported as 'sometimes/ often' consumed by $75 \%, 70 \%$ and $56 \%$ of men, respectively, and $66 \%, 61 \%$ and $65 \%$ of women, respectively.

Comparisons of baseline characteristics by the presence of a first CHD event are shown in Table 2. Participants who developed CHD were significantly older $(P<0 \cdot 001)$, had higher BMI $(P=0.035)$ and higher total cholesterol $(P=0 \cdot 050)$, and were more likely to be male $(P<0 \cdot 001)$, diabetic $(P=0 \cdot 011)$ and hypertensive $(P<0 \cdot 001)$, than those who did not develop CHD. No significant differences between CHD cases and non-cases were observed for alcohol consumption, TAG, HDL-cholesterol, smoking, exercise or current oestrogen use (in women). There were no differences in baseline dairy consumption between participants with or without incident CHD (all $P>0 \cdot 10$; Table 3).

Results of Cox proportional hazard models examining the time-to-event association of dairy product intake with incident CHD after adjustment for CHD risk factors, including age, BMI, diabetes, hypertension, LDL-cholesterol and current oestrogen use (in women), are shown in Table 4 for both men and women. In partially adjusted and fully adjusted models, there were no significant associations between CHD and dairy product consumption in men (see Table 4).

In unadjusted models (not shown), women had an increased risk of CHD if they 'sometimes/often' consumed non-fat milk as compared with 'never/rarely' consuming non-fat milk ( $\mathrm{HR}=1 \cdot 49$; $95 \%$ CI $1 \cdot 10,2 \cdot 03$ ) and if they 'sometimes/often' consumed low-fat cheese as compared with 'never/rarely' consuming low-fat cheese ( $\mathrm{HR}=1 \cdot 68 ; 95 \%$ CI $1 \cdot 21,2 \cdot 35)$. After adjusting for age and BMI, women who 'sometimes/often' as compared with 'never/rarely' consumed non-fat milk had a significantly increased risk of CHD (HR $=1 \cdot 55$; $95 \%$ CI $1 \cdot 14$, $2 \cdot 12)$ that was slightly attenuated but stayed significant after adjusting for all other $\mathrm{CHD}$ risk factors $(\mathrm{HR}=1 \cdot 48$; 95\% CI 1.02, 2.16; Table 4). Likewise, women who consumed low-fat cheese 'sometimes/often' as compared with 'never/rarely' had a significantly increased risk of CHD ( $\mathrm{HR}=2 \cdot 32 ; 95 \% \mathrm{CI} 1 \cdot 57,3 \cdot 41)$ in the multivariate analyses adjusting for all CHD risk factors. The survival curves of these associations are plotted in Figs 1 and 2, 
Table 1 Demographic characteristics of Rancho Bernardo participants, 1984-1987 (n 1759)

\begin{tabular}{|c|c|c|c|c|}
\hline \multirow[b]{2}{*}{ Variable } & \multicolumn{2}{|c|}{ Men $(n 751)$} & \multicolumn{2}{|c|}{ Women (n 1008) } \\
\hline & Mean & SD & Mean & SD \\
\hline Age (years) & $70 \cdot 6$ & $9 \cdot 8$ & $70 \cdot 1$ & $9 \cdot 3$ \\
\hline $\mathrm{BMl}\left(\mathrm{kg} / \mathrm{m}^{2}\right)$ & $25 \cdot 9$ & $3 \cdot 3$ & $24 \cdot 1$ & $3 \cdot 7$ \\
\hline Total cholesterol (mg/dl) & $212 \cdot 4$ & $54 \cdot 9$ & $234 \cdot 8$ & $78 \cdot 3$ \\
\hline HDL-cholesterol (mg/dl) & $54 \cdot 2$ & $14 \cdot 6$ & $70 \cdot 1$ & $18 \cdot 7$ \\
\hline LDL-cholesterol (mg/dl) & $134 \cdot 6$ & $56 \cdot 1$ & $144 \cdot 1$ & $85 \cdot 1$ \\
\hline \multirow[t]{2}{*}{ TAG $(\mathrm{mg} / \mathrm{dl})$} & $122 \cdot 3$ & $88 \cdot 5$ & $110 \cdot 3$ & $63 \cdot 8$ \\
\hline & Median & IQR & Median & IQR \\
\hline \multirow[t]{2}{*}{ Alcohol (g/week) } & $4 \cdot 8$ & $4 \cdot 1-5 \cdot 3$ & $4 \cdot 6$ & $3 \cdot 9-5 \cdot 1$ \\
\hline & $n$ & $\%$ & $n$ & $\%$ \\
\hline Diabetes & 116 & $15 \cdot 5$ & 97 & $9 \cdot 6$ \\
\hline Hypertension & 544 & $72 \cdot 4$ & 700 & $69 \cdot 4$ \\
\hline \multicolumn{5}{|l|}{ Smoking } \\
\hline Current & 80 & $10 \cdot 7$ & 151 & $15 \cdot 0$ \\
\hline Former & 444 & $59 \cdot 1$ & 371 & $36 \cdot 8$ \\
\hline Never & 227 & $30 \cdot 2$ & 486 & $48 \cdot 2$ \\
\hline Strenuous exercise $\geq 3$ times/week & 640 & $85 \cdot 2$ & 798 & $79 \cdot 2$ \\
\hline Current oestrogen user* & - & $0 \cdot 0$ & 402 & $39 \cdot 9$ \\
\hline Dairy product consumption & $\begin{array}{c}\text { Sometimes/oftent } \\
(\%)\end{array}$ & $\begin{array}{c}\text { Never/rarely } \ddagger \\
(\%)\end{array}$ & $\begin{array}{c}\text { Sometimes/oftent } \\
(\%)\end{array}$ & $\begin{array}{c}\text { Never/rarely } \neq \\
(\%)\end{array}$ \\
\hline Cheese & $92 \cdot 4$ & $7 \cdot 6$ & $90 \cdot 1$ & $9 \cdot 9$ \\
\hline Ice cream & $75 \cdot 4$ & $24 \cdot 6$ & $65 \cdot 9$ & $34 \cdot 1$ \\
\hline Whole milk & $69 \cdot 8$ & $30 \cdot 2$ & $61 \cdot 4$ & $38 \cdot 6$ \\
\hline Cottage cheese & $55 \cdot 7$ & $44 \cdot 3$ & $65 \cdot 1$ & 34.9 \\
\hline Milk chocolate & $45 \cdot 1$ & $54 \cdot 9$ & $43 \cdot 6$ & $56 \cdot 4$ \\
\hline Butter & $38 \cdot 8$ & $61 \cdot 2$ & $33 \cdot 6$ & $66 \cdot 4$ \\
\hline Cream & $32 \cdot 4$ & $67 \cdot 6$ & 33.9 & $66 \cdot 1$ \\
\hline Non-fat milk & $32 \cdot 2$ & $67 \cdot 8$ & $40 \cdot 0$ & $60 \cdot 0$ \\
\hline Yoghurt & $24 \cdot 8$ & $75 \cdot 2$ & $40 \cdot 0$ & $60 \cdot 0$ \\
\hline Cream cheese & $21 \cdot 9$ & $78 \cdot 1$ & $25 \cdot 2$ & $74 \cdot 8$ \\
\hline Hot cocoa & $16 \cdot 4$ & $83 \cdot 6$ & $14 \cdot 7$ & $85 \cdot 3$ \\
\hline Low-fat cheese & $15 \cdot 7$ & $84 \cdot 3$ & $23 \cdot 6$ & $76 \cdot 4$ \\
\hline
\end{tabular}

IQR, interquartile range.

Due to rounding, percentages may not add up to 100 .

${ }^{*}$ Assessed only in women, $n 721$.

tSometimes/often includes 1-3 times/month, 1-3 times/week, 4-6 times/week and daily.

$\ddagger$ Never/rarely includes never and 1-11 times/year.

respectively. As shown in Figs 1 and 2, there is clear separation of survival risk for women according to high or low intake of non-fat milk and low-fat cheese.

\section{Discussion}

In the present study consumption of dairy products, in general, was not related to incident CHD. However, we did find that women who 'sometimes/often' consumed non-fat milk and women who 'sometimes/often' consumed low-fat cheese had a significantly increased risk of incident CHD compared with those who 'never/rarely' consumed these dairy products, after including the known covariates of CHD mortality in the model.

We found no association between intake of the majority of the dairy products and CHD, a finding consistent with previous literature ${ }^{(15,17,20,23,32,36,37)}$. For example, in a case-control study of 378 men and 129 women aged
25-79 years, Tavani et al. concluded that neither total milk, whole milk, semi-skimmed milk, yoghurt nor cheese was associated with increased CHD risk in men and women ${ }^{(1)}$. Likewise, no significant association was found for milk and butter consumption among the 2818 men in the prospective British Regional Heart Study ${ }^{(38)}$. In a more recent casecontrol study conducted in Costa Rican adults, dairy product intake (butter, buttermilk, cheeses, cream, ice cream, lactocrema, milk and yoghurt), as assessed by adipose tissue and by FFQ, was not associated with an increase in the risk of myocardial infarction ${ }^{(28)}$.

The results of the present study by gender are in contrast to several other studies that report dairy intake increases CHD risk. In a recent population-based cohort study of rural Swedish men with 12 years of follow-up, men who consumed low-fat dairy compared with high-fat dairy were 1.43 times more likely to have $\mathrm{CHD}^{(33)}$. The Nurses' Health Study found that the ratio of high-fat to low-fat dairy food consumption was positively associated with an 
Table 2 Age-adjusted comparison characteristics in participants with and without CHD, Rancho Bernardo, 1984-1987

\begin{tabular}{|c|c|c|c|c|c|}
\hline \multirow[b]{2}{*}{ Variable } & \multicolumn{2}{|c|}{ Non-CHD cases ( $n$ 1308) } & \multicolumn{2}{|c|}{ CHD cases $(n 451)$} & \multirow[b]{2}{*}{$P^{\star}$} \\
\hline & Mean & SD & Mean & SD & \\
\hline Age (years) & $69 \cdot 6$ & $9 \cdot 7$ & $72 \cdot 3$ & $8 \cdot 5$ & 0.001 \\
\hline BMI $\left(\mathrm{kg} / \mathrm{m}^{2}\right)$ & $24 \cdot 7$ & $3 \cdot 6$ & $25 \cdot 1$ & $3 \cdot 9$ & 0.035 \\
\hline Total cholesterol (mg/dl) & $223 \cdot 9$ & $68 \cdot 7$ & $229 \cdot 1$ & $74 \cdot 0$ & 0.050 \\
\hline HDL-cholesterol (mg/dl) & $64 \cdot 3$ & $18 \cdot 9$ & $60 \cdot 3$ & $18 \cdot 3$ & 0.407 \\
\hline LDL-cholesterol (mg/dl) & $138 \cdot 1$ & $72 \cdot 6$ & $145 \cdot 5$ & $78 \cdot 6$ & 0.038 \\
\hline \multirow[t]{2}{*}{ TAG (mg/dl) } & $112 \cdot 8$ & $74 \cdot 4$ & $123 \cdot 0$ & $78 \cdot 3$ & $0 \cdot 184$ \\
\hline & Median & IQR & Median & IQR & \\
\hline \multirow[t]{2}{*}{ Alcohol (g/week) } & $4 \cdot 6$ & $4 \cdot 0-5 \cdot 3$ & $4 \cdot 7$ & $3 \cdot 9-5 \cdot 3$ & $0 \cdot 389$ \\
\hline & $n$ & $\%$ & $n$ & $\%$ & \\
\hline Men & 529 & $40 \cdot 4$ & 222 & $49 \cdot 2$ & 0.001 \\
\hline Diabetes & 142 & $11 \cdot 0$ & 69 & $15 \cdot 5$ & $0 \cdot 011$ \\
\hline Hypertension & 897 & $68 \cdot 6$ & 346 & $76 \cdot 7$ & 0.001 \\
\hline Smoking & & & & & 0.401 \\
\hline Current & 173 & $13 \cdot 2$ & 58 & $12 \cdot 9$ & \\
\hline Former & 594 & $45 \cdot 4$ & 221 & $49 \cdot 0$ & \\
\hline Never & 541 & $41 \cdot 4$ & 172 & $38 \cdot 1$ & \\
\hline Strenuous exercise $\geq 3$ times/week & 1075 & $82 \cdot 2$ & 363 & $80 \cdot 5$ & 0.421 \\
\hline Current oestrogen usert & 220 & $41 \cdot 3$ & 61 & $35 \cdot 5$ & $0 \cdot 176$ \\
\hline
\end{tabular}

IQR, interquartile range.

Due to rounding, percentages may not add up to 100 .

Alcohol was log transformed.

${ }^{*} P$ value from $t$ test for continuous variables and from $\chi^{2}$ test for categorical variables.

tAssessed only in women.

increased risk of CHD among women ${ }^{(6)}$. More recently, the Nurses' Health Study found that a high-fat dairy diet in combination with a higher intake of red meat was significantly associated with elevated risk of $\mathrm{CHD}^{(29)}$. A case-control study showed that only butter (but not cheese, yoghurt, low-fat dairy or high-fat milk) was significantly positively associated with the risk of first myocardial infarction ${ }^{(53)}$.

The null results of the present study for dairy product consumption and CHD observed in men and the positive associations of dairy product consumption with CHD in women are somewhat comparable to a Dutch study examining dairy consumption and 10-year total and cardiovascular death. In that study of 16136 men and women, researchers found low-fat cheese intake in men was associated with a small increased risk of all-cause mortality ${ }^{(30)}$. The CARDIO2000 multicentre case-control study found that consumption of milk, cheese and yoghurt in 700 and 148 Greek men and women, respectively, was significantly associated with lower odds of having acute coronary events, specifically acute myocardial infarction and unstable angina $(\mathrm{OR}=0 \cdot 88 ; 95 \% \mathrm{CI} 0 \cdot 83,0 \cdot 93)^{(34)}$. One other study did find a similar association between cheese consumption and CHD in women. Sonestedt et al. explored the association between the intake of specific dairy products and incidence of CHD among 26445 middle-aged men and women in the Swedish Malmö Diet and Cancer (MDC) cohort. Cheese intake was significantly associated with decreased CHD risk in women but not in men ${ }^{(40)}$. The absence of a clear consistent association between dairy and
CHD could be due to inconsistent study designs. While ecological studies were the first to report an association between dairy consumption and CHD, ecological studies are typically regarded as weaker studies because they are susceptible to the ecological fallacy. Case-control studies are used to identify factors that may contribute to a medical condition by comparing individuals who have a disease with individuals who do not have the disease but are otherwise similar. A limitation to case-control studies is that they rely on memory and are subject to recall bias (people with a condition will be more motivated to recall risk factors). Case-control studies can only assess association, not causation. Cohort studies follow a population over time to determine which risk factors are associated with the development of a disease or outcome. Since information on risk factors is ascertained before development of disease, cohort studies can infer causation. Meta-analyses have the highest level on the hierarchy of evidence. A meta-analysis is a method for systematically combining pertinent qualitative and quantitative study data from several selected studies to develop a single conclusion that has greater statistical power. This conclusion is statistically stronger than the analysis of any single study, due to increased numbers of subjects, greater diversity among subjects, and/or accumulated effects and results. Previous smallsample studies, and/or relatively short follow-up, may be insufficient to assess mortality. Some studies did not include both sexes and/or included younger participants who are at low risk for CHD. Additionally, most previous studies failed to report whole and non-fat dairy separately and excluded 
Table 3 Age-adjusted comparisons of participants with and without incident CHD on dairy characteristics, Rancho Bernardo, 1984-1987

\begin{tabular}{|c|c|c|c|}
\hline Variable & Non-CHD & $\mathrm{CHD}$ & $P^{\star}$ \\
\hline \multicolumn{4}{|l|}{ Whole milk } \\
\hline Sometimes/oftent (\%) & $64 \cdot 5$ & 65.9 & \multirow[t]{2}{*}{0.59} \\
\hline Never/rarely $\ddagger$ (\%) & $35 \cdot 5$ & $34 \cdot 1$ & \\
\hline \multicolumn{4}{|l|}{ Non-fat milk } \\
\hline Sometimes/oftent (\%) & $36 \cdot 0$ & $37 \cdot 8$ & \multirow[t]{2}{*}{0.49} \\
\hline Never/rarely $¥$ (\%) & $64 \cdot 0$ & $62 \cdot 2$ & \\
\hline \multicolumn{4}{|l|}{ Cheese } \\
\hline Sometimes/oftent (\%) & $91 \cdot 6$ & $89 \cdot 4$ & \multirow{2}{*}{$0 \cdot 16$} \\
\hline Never/rarely $(\%)$ & $8 \cdot 4$ & $10 \cdot 6$ & \\
\hline \multicolumn{4}{|l|}{ Butter } \\
\hline Sometimes/oftent (\%) & $36 \cdot 9$ & 33.6 & \multirow[t]{2}{*}{$0 \cdot 22$} \\
\hline Never/rarely $\ddagger(\%)$ & $63 \cdot 1$ & $66 \cdot 4$ & \\
\hline \multicolumn{4}{|l|}{ Ice cream } \\
\hline Sometimes/oftent (\%) & $69 \cdot 4$ & $71 \cdot 0$ & \multirow[t]{2}{*}{0.55} \\
\hline Never/rarely $¥$ (\%) & $30 \cdot 6$ & $29 \cdot 0$ & \\
\hline \multicolumn{4}{|l|}{ Cottage cheese } \\
\hline Sometimes/oftent (\%) & $60 \cdot 6$ & $61 \cdot 1$ & \multirow[t]{2}{*}{$0 \cdot 85$} \\
\hline Never/rarely $\ddagger$ (\%) & $39 \cdot 5$ & 38.9 & \\
\hline \multicolumn{4}{|l|}{ Yoghurt } \\
\hline Sometimes/oftent (\%) & $33 \cdot 5$ & $32 \cdot 3$ & \multirow{2}{*}{0.63} \\
\hline Never/rarely $\ddagger$ (\%) & $66 \cdot 5$ & $67 \cdot 7$ & \\
\hline \multicolumn{4}{|l|}{ Cream } \\
\hline Sometimes/oftent (\%) & $33 \cdot 3$ & 33.6 & \multirow[t]{2}{*}{0.90} \\
\hline Never/rarelył (\%) & $66 \cdot 7$ & $66 \cdot 4$ & \\
\hline \multicolumn{4}{|l|}{ Milk chocolate } \\
\hline Sometimes/oftent (\%) & $44 \cdot 9$ & $41 \cdot 7$ & \multirow[t]{2}{*}{$0 \cdot 24$} \\
\hline Never/rarely $\ddagger$ (\%) & $55 \cdot 1$ & $58 \cdot 3$ & \\
\hline \multicolumn{4}{|l|}{ Low-fat cheese } \\
\hline Sometimes/oftent (\%) & $19 \cdot 4$ & $21 \cdot 0$ & \multirow[t]{2}{*}{$0 \cdot 47$} \\
\hline Never/rarely‡ (\%) & $80 \cdot 6$ & $79 \cdot 0$ & \\
\hline \multicolumn{4}{|l|}{ Cream cheese } \\
\hline Sometimes/oftent (\%) & $23 \cdot 1$ & $24 \cdot 9$ & \multirow[t]{2}{*}{$0 \cdot 45$} \\
\hline Never/rarely $\ddagger$ (\%) & $76 \cdot 9$ & $75 \cdot 1$ & \\
\hline \multicolumn{4}{|l|}{ Hot chocolate } \\
\hline Sometimes/oftent (\%) & $15 \cdot 4$ & $14 \cdot 1$ & \multirow[t]{2}{*}{$0 \cdot 51$} \\
\hline Never/rarelył (\%) & $84 \cdot 6$ & $85 \cdot 9$ & \\
\hline
\end{tabular}

Due to rounding, percentages may not add up to 100 .

${ }^{*} P$ value from $\chi^{2}$ test.

+Sometimes/often includes daily, 4-6 times/week, 1-3 times/week and 1-3 times/month.

‡Rarely/never includes never and 1-11 times/year. information on consumption of other types of dairy products (cream, cheese, butter). A double-blind randomized controlled study by Malpuech-Brugere et al., which examined the impact of milk fats on CVD risk factors, found that consumption of dairy fat with naturally present ruminant total trans-fatty acids (different from the industrially manufactured harmful trans-fatty acids) improved some CVD risk factors (decrease in total cholesterol, decrease in LDL-cholesterol and decrease in LDL-cholesterol:HDLcholesterol) for healthy volunteers in comparison to a dairy fat diet with low total trans-fatty acids ${ }^{(31)}$. The levels of ruminant trans-fatty acids in dairy fats is influenced by the type of diet the cows feed on ${ }^{(54)}$. Another study by Mozaffarian et al. reported on plasma trans-palmitoleic acid (one of the above-mentioned dairy trans-fatty acids), which was found to be highly correlated with intake of whole-fat dairy products and to predict lower incidence of type 2 diabetes and a favourable metabolic profile ${ }^{(55)}$. These recent studies may explain the negative association of dairy products and risk of CVD, and support the higher risk of CVD among women who consumed low-fat cheese found in our study.

The present study is the first to report an increase in CHD mortality among women due to non-fat milk and low-fat cheese consumption. Although not commonly advocated at the time, women with high levels of cholesterol at baseline in 1984-1987 may have been told to limit dairy to non-fat forms. Our results may also be due to having a family history of CHD; we could not verify these reports in the present study. It should also be noted that the association observed between 'sometimes/often' and 'never/rarely' consumed low-fat cheese in women includes a small number of individuals in this category. Several limitations of the study should be noted. This sample of

Table 4 Crude and adjusted associations of dairy consumption with risk of incident CHD morbidity and mortality, Rancho Bernardo, 1984-1987 and 2007

\begin{tabular}{|c|c|c|c|c|c|c|c|c|}
\hline \multirow[b]{3}{*}{ Variable } & \multicolumn{4}{|c|}{ Men } & \multicolumn{4}{|c|}{ Women } \\
\hline & \multicolumn{2}{|c|}{ Model $1^{*}$} & \multicolumn{2}{|c|}{ Model $2 \dagger$} & \multicolumn{2}{|c|}{ Model $1 \ddagger$} & \multicolumn{2}{|c|}{ Model $2 \S$} \\
\hline & $\mathrm{HR}$ & $95 \% \mathrm{Cl}$ & HR & $95 \% \mathrm{Cl}$ & $\mathrm{HR}$ & $95 \% \mathrm{Cl}$ & $\mathrm{HR}$ & $95 \% \mathrm{Cl}$ \\
\hline Non-fat milk & 1.05 & $0.76,1.45$ & $1 \cdot 08$ & $0.78,1.49$ & 1.55 & $1 \cdot 14,2 \cdot 12$ & 1.48 & $1 \cdot 02,2 \cdot 16$ \\
\hline Yoghurt & $1 \cdot 16$ & $0.83,1.63$ & $1 \cdot 20$ & $0.85,1.68$ & $1 \cdot 12$ & $0.81,1.54$ & 1.32 & $0.90,1.92$ \\
\hline Ice cream & $1 \cdot 25$ & $0.88,1.78$ & $1 \cdot 25$ & $0.88,1.79$ & 0.93 & $0 \cdot 67,1 \cdot 30$ & 0.96 & $0.64,1.45$ \\
\hline Low-fat cheese & 0.96 & $0.64,1.44$ & 0.98 & $0.65,1.46$ & $1 \cdot 72$ & $1 \cdot 23,2 \cdot 41$ & $2 \cdot 32$ & $1 \cdot 57,3 \cdot 41$ \\
\hline Cheese & $1 \cdot 20$ & $0 \cdot 68,2 \cdot 11$ & $1 \cdot 23$ & $0 \cdot 70,2 \cdot 18$ & 0.81 & $0 \cdot 52,1 \cdot 26$ & 0.71 & $0.43,1.20$ \\
\hline Cottage cheese & $1 \cdot 19$ & $0.87,1.61$ & $1 \cdot 21$ & $0.89,1.66$ & 0.84 & $0 \cdot 61,1 \cdot 16$ & 1.04 & $0.71,1.53$ \\
\hline Cream & 0.94 & $0.68,1.31$ & 0.94 & $0.68,1.31$ & $1 \cdot 15$ & $0.83,1.60$ & $1 \cdot 10$ & $0.74,1.62$ \\
\hline Cream cheese & 1.00 & $0.70,1.43$ & $1 \cdot 03$ & $0.72,1.48$ & 1.29 & $0.92,1 \cdot 80$ & 1.33 & $0.89,1.99$ \\
\hline Whole milk & 1.00 & $0.72,1.39$ & 0.99 & $0.71,1.38$ & 1.05 & $0.76,1.45$ & 1.01 & $0.68,1.49$ \\
\hline Milk chocolate & $0 \cdot 88$ & $0.65,1.20$ & $0 \cdot 88$ & $0.64,1.20$ & 0.99 & $0 \cdot 72,1 \cdot 35$ & 1.06 & $0.73,1.53$ \\
\hline Butter & 1.04 & $0.76,1.42$ & $1 \cdot 06$ & $0.77,1.46$ & 0.86 & $0.61,1 \cdot 22$ & 0.88 & $0.58,1.33$ \\
\hline Hot chocolate & 0.91 & $0.58,1.43$ & 0.96 & $0.61,1.51$ & 0.92 & $0.59,1.45$ & 0.91 & $0.53,1.54$ \\
\hline
\end{tabular}

HR, hazard ratio.

Significant associations are shown in bold font.

*Adjusted for age and BMI.

tAdjusted for age, BMI, diabetes, hypertension and LDL-cholesterol.

$\ddagger$ Adjusted for age and BMI.

$\S$ Adjusted for age, BMI, diabetes, hypertension, LDL-cholesterol and current oestrogen use. 


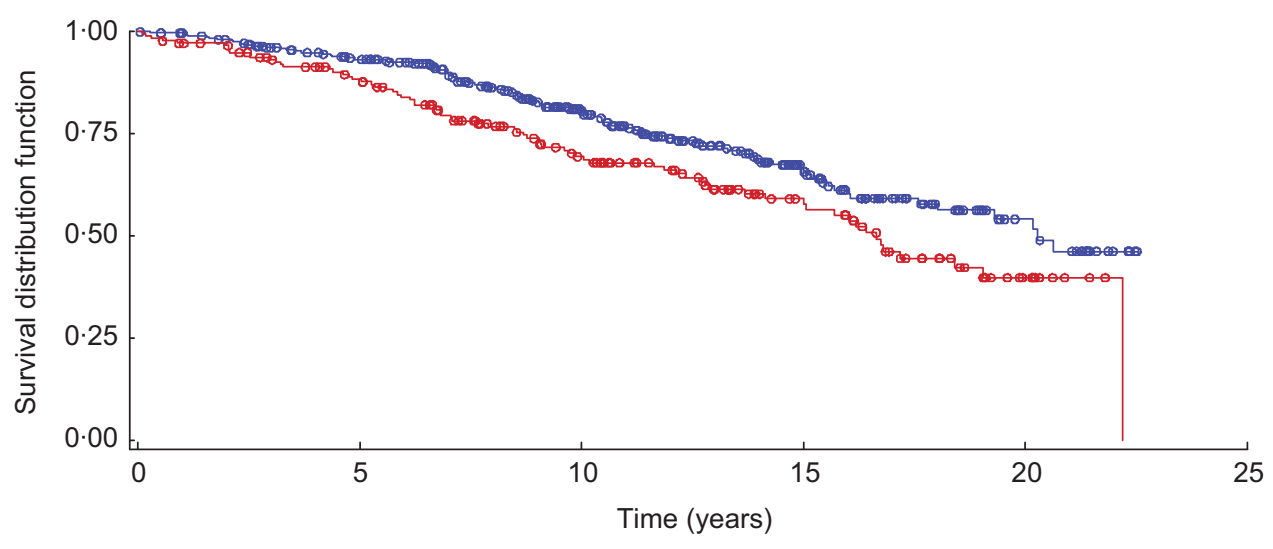

Strata: - MILKF $=0000$ Censored MILKF $=0-$ MILKF $=1000$ Censored MILKF = 1
- Never/rarely consumed non-fat milk - Sometimes/often consumed non-fat milk

Fig. 1 (colour online) Hazard curve of non-fat milk (MLKF) consumption in Rancho Bernardo women with risk of incident CHD morbidity and mortality, 1984-1987 and 2007

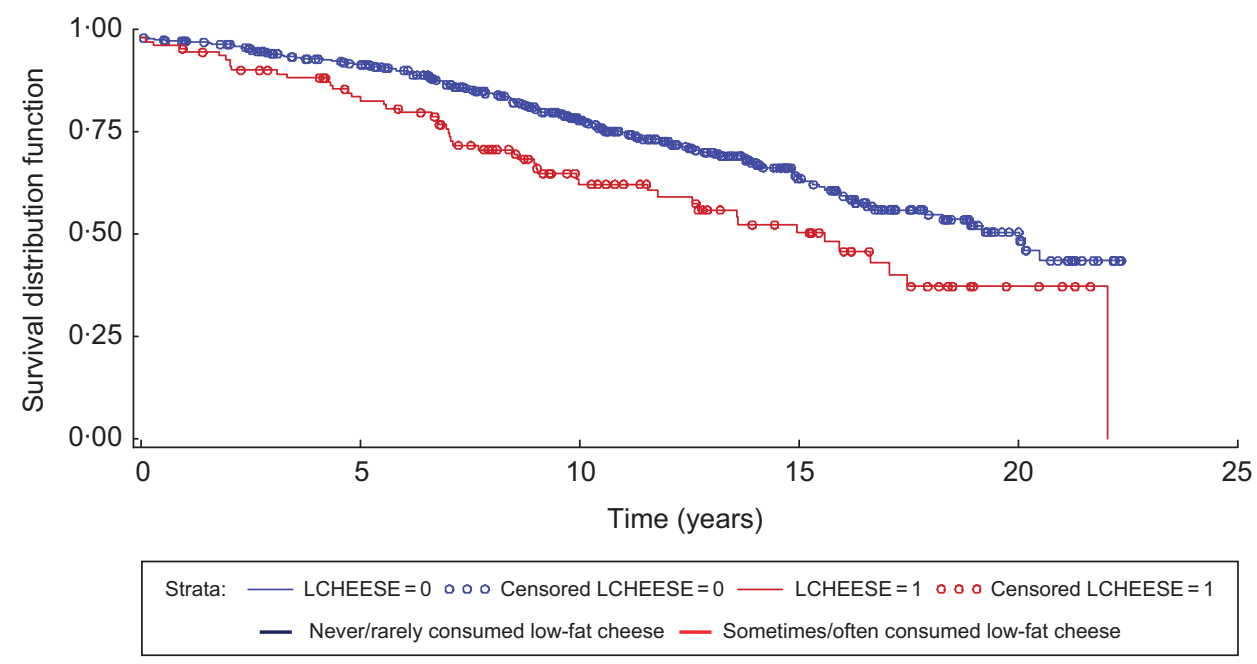

Fig. 2 (colour online) Hazard curve of low-fat cheese (LCHEESE) consumption in Rancho Bernardo women with risk of incident CHD morbidity and mortality, 1984-1987 and 2007

community-dwelling, older, Caucasian, middle-class adults living in southern California may not be representative of the general US population, thus limiting the generalizability of the results. However, this homogeneity means that associations are less confounded by socio-economic status and ethnicity. Additionally, exercise, smoking, alcohol consumption and dairy consumption were all selfreported. However, the high educational level of this cohort makes it more likely that self-reports are valid. In Rancho Bernardo participants, self-reported alcohol intake was indirectly validated by parallel increases in HDLcholesterol with increasing alcohol intake, a well-known consequence of alcohol consumption ${ }^{(56,57)}$. Participation bias - whereby those who were ill may not have participated - cannot be excluded. A limitation of exposure assessment was the need to combine categories of dairy and milk intake due to small sample size within the original categories of frequency of intake. Although this could have attenuated the association, we kept the participants who rarely used these products as a well-defined group and compared them with all others. Dairy consumption was measured with a validated FFQ, which was based on self-reported intake. This may have introduced misclassification of dairy intake, which could have attenuated the associations. However, an advantage of the FFQ is that it measures food consumption over a year, which is relevant for chronic diseases ${ }^{(58)}$. The positive associations observed in the present study could be a chance finding due to multiple comparisons, and further studies with larger sample size need to specifically address these associations. However, recent evidence does provide biological plausibility of these associations ${ }^{(6,33)}$. 
The present study also has a number of strengths. Its prospective design allows for investigation of the risk of CHD mortality associated with dairy consumption over a 20-year follow-up period and avoids recall bias. We obtained robust hazard estimates and plots of adjusted cumulative probability of mortality over time while controlling for confounding and adjusting for minimal loss to follow-up. The uniquely characterized population is at an increased risk of CHD because of their much older age than most previous study populations, therefore increasing the potential for finding any true association with dairy intake.

\section{Conclusions}

Dairy product consumption assessed in a sample of older men and women was not statistically associated with $\mathrm{CHD}$, providing assurance to elderly who need dairy $\mathrm{Ca}$ sources to maintain healthy bones. Non-fat milk and low-fat cheese intake among women were related to $\mathrm{CHD}$, an association that requires further investigation in other cohort studies that utilize measures of different dairy fats.

\section{Acknowledgements}

Source of funding: The study was supported by grants AG007181 and AG028507 from the National Institutes of Health/National Institute on Aging, and by grant DK31801 from the National Institute of Diabetes and Digestive and Kidney Diseases. Conflicts of interest: The authors have no conflicts of interest. Authors' contributions: E.E.A. conducted the statistical analyses and drafted the manuscript; W.K.A.-D. planned the study hypotheses and statistical analyses, revised the drafts and approved the final manuscript; E.B.-C. planned the original Rancho Bernardo study, revised the statistical analyses and manuscript drafts and approved the final manuscript; J.N.B. assisted with the data collection and statistical analyses; D.L.W. revised the statistical analyses and manuscript drafts and approved the final manuscript; D.K.-S. revised the statistical analyses and manuscript drafts and approved the final manuscript.

\section{References}

1. Tavani A, Gallus S, Negri E et al. (2002) Milk, dairy products, and coronary heart disease. J Epidemiol Community Health 56, $471-472$.

2. Kushi LH, Lenart EB \& Willett WC (1995) Health implications of Mediterranean diets in light of contemporary knowledge. 1. Plant foods and dairy products. Am J Clin Nutr 61, 6 Suppl., 1407S-1415S.

3. Renaud S \& de Lorgeril M (1989) Dietary lipids and their relation to ischaemic heart disease: from epidemiology to prevention. J Intern Med Suppl 731, 39-46.

4. Moss M \& Freed DL (1999) Survival trends, coronary event rates, and the MONICA project. Monitoring trends and determinants in cardiovascular disease. Lancet 354, 862; author reply 863-864.

5. Menotti A, Kromhout D, Blackburn H et al. (1999) Food intake patterns and 25-year mortality from coronary heart disease: cross-cultural correlations in the Seven Countries Study. The Seven Countries Study Research Group. Eur J Epidemiol 15, 507-515.

6. Hu FB, Stampfer MJ, Manson JE et al. (1999) Dietary saturated fats and their food sources in relation to the risk of coronary heart disease in women. Am J Clin Nutr 70, 1001-1008.

7. Segall JJ (1994) Dietary lactose as a possible risk factor for ischaemic heart disease: review of epidemiology. Int $J$ Cardiol 46, 197-207.

8. Seely S (1981) Diet and coronary disease: a survey of mortality rates and food consumption statistics of 24 countries. Med Hypotheses 7, 907-918.

9. Seely S (1981) Diet and coronary heart disease: a survey of female mortality rates and food consumption statistics of 21 countries. Med Hypotheses 7, 1133-1137.

10. Lamarche B (2008) Review of the effect of dairy products on non-lipid risk factors for cardiovascular disease. $\mathrm{J} \mathrm{Am}$ Coll Nutr 27, issue 6, 741S-746S.

11. Biong AS, Veierod MB, Ringstad J et al. (2006) Intake of milk fat, reflected in adipose tissue fatty acids and risk of myocardial infarction: a case-control study. Eur J Clin Nutr 60, 236-244.

12. German JB, Gibson RA, Krauss RM et al. (2009) A reappraisal of the impact of dairy foods and milk fat on cardiovascular disease risk. Eur J Nutr 48, 191-203.

13. Wang L, Manson JE, Song Y et al. (2010) Systematic review: vitamin D and calcium supplementation in prevention of cardiovascular events. Ann Intern Med 152, 315-323.

14. Elwood PC, Givens DI, Beswick AD et al. (2008) The survival advantage of milk and dairy consumption: an overview of evidence from cohort studies of vascular diseases, diabetes and cancer. J Am Coll Nutr 27, issue 6, 723S-734S.

15. Soedamah-Muthu SS, Ding EL, Al-Delaimy WK et al. (2011) Milk and dairy consumption and incidence of cardiovascular diseases and all-cause mortality: dose-response metaanalysis of prospective cohort studies. Am J Clin Nutr 93, 158-171.

16. Al-Delaimy WK (2008) Commentary: lactose and ischaemic heart disease: a weak 28-year-old hypothesis. Int $J$ Epidemiol 37, 1214-1216.

17. Grant WB (2008) Commentary: ecologic studies in identifying dietary risk factors for coronary heart disease and cancer. Int J Epidemiol 37, 1209-1211.

18. Ness AR, Smith GD \& Hart C (2001) Milk, coronary heart disease and mortality. J Epidemiol Community Health 55, 379-382.

19. Appleby PN, Thorogood M, Mann JI et al. (1999) The Oxford Vegetarian Study: an overview. Am J Clin Nutr 70, 3 Suppl., 525S-531S.

20. Bostick RM, Kushi LH, Wu Y et al. (1999) Relation of calcium, vitamin D, and dairy food intake to ischemic heart disease mortality among postmenopausal women. Am J Epidemiol 149, 151-161.

21. Elwood PC, Pickering JE, Fehily AM et al. (2004) Milk drinking, ischaemic heart disease and ischaemic stroke I. Evidence from the Caerphilly cohort. Eur J Clin Nutr $\mathbf{5 8}$, 711-717.

22. Mann JI, Appleby PN, Key TJ et al. (1997) Dietary determinants of ischaemic heart disease in health conscious individuals. Heart 78, 450-455.

23. Snowdon DA, Phillips RL \& Fraser GE (1984) Meat consumption and fatal ischemic heart disease. Prev Med 13, 490-500.

24. Elwood PC, Pickering JE, Hughes J et al. (2004) Milk drinking, ischaemic heart disease and ischaemic stroke II. Evidence from cohort studies. Eur J Clin Nutr 58, 718-724. 
25. Gibson RA, Makrides M, Smithers LG et al. (2009) The effect of dairy foods on CHD: a systematic review of prospective cohort studies. Br J Nutr 102, 1267-1275.

26. Panagiotakos D, Pitsavos C, Chrysohoou C et al. (2009) Dietary patterns and 5-year incidence of cardiovascular disease: a multivariate analysis of the ATTICA study. Nutr Metab Cardiovasc Dis 19, 253-263.

27. Al-Delaimy WK, Rimm E, Willett WC et al. (2003) A prospective study of calcium intake from diet and supplements and risk of ischemic heart disease among men. Am J Clin Nutr 77, 814-818.

28. Aslibekyan S, Campos H \& Baylin A (2011) Biomarkers of dairy intake and the risk of heart disease. Nutr Metab Cardiovasc Dis (Epublication ahead of print version).

29. Bernstein AM, Sun Q, Hu FB et al. (2010) Major dietary protein sources and risk of coronary heart disease in women. Circulation 122, 876-883.

30. Goldbohm RA, Chorus AM, Galindo GF et al. (2011) Dairy consumption and 10-y total and cardiovascular mortality: a prospective cohort study in the Netherlands. Am J Clin Nutr 93, 615-627.

31. Malpuech-Brugere C, Mouriot J, Boue-Vaysse C et al. (2010) Differential impact of milk fatty acid profiles on cardiovascular risk biomarkers in healthy men and women. Eur J Clin Nutr 64, 752-759.

32. Umesawa M, Iso H, Ishihara J et al. (2008) Dietary calcium intake and risks of stroke, its subtypes, and coronary heart disease in Japanese - The JPHC Study Cohort I. Stroke 39, 2449-2456.

33. Holmberg S, Thelin A \& Stiernstrom E-L (2009) Food choices and coronary heart disease: a population based cohort study of rural Swedish men with 12 years of followup. Int J Environ Res Public Health 6, 2626-2638.

34. Kontogianni MD, Panagiotakos DB, Chrysohoou C et al. (2006) Modelling dairy intake on the development of acute coronary syndromes: the CARDIO2000 study. Eur $J$ Cardiovasc Prev Rehab 13, 791-797.

35. Kant AK, Leitzmann ME, Park Y et al. (2009) Patterns of recommended dietary behaviors predict subsequent risk of mortality in a large cohort of men and women in the United States. J Nutr 139, 1374-1380.

36. Trichopoulou A, Bamia C \& Trichopoulos D (2009) Anatomy of health effects of Mediterranean diet: Greek EPIC prospective cohort study. BMJ 338, b2337.

37. van der Pols JC, Gunnell D, Williams GM et al. (2009) Childhood dairy and calcium intake and cardiovascular mortality in adulthood: 65-year follow-up of the Boyd Orr cohort. Heart 95, 1600-1606.

38. Shaper AG, Wannamethee G \& Walker M (1991) Milk, butter, and heart disease. BMJ 302, 785-786.

39. Lockheart MSK, Steffen LM, Rebnord HM et al. (2007) Dietary patterns, food groups and myocardial infarction: a case-control study. Br J Nutr 98, 380-387.

40. Sonestedt E, Wirfalt E, Wallstrom P et al. (2011) Dairy products and its association with incidence of cardiovascular disease: the Malmo diet and cancer cohort. Eur J Epidemiol 26, 609-618.

41. Brunner EJ, Mosdol A, Witte DR et al. (2008) Dietary patterns and 15-y risks of major coronary events, diabetes, and mortality. Am J Clin Nutr 87, 1414-1421.
42. Massey LK (2001) Dairy food consumption, blood pressure and stroke. J Nutr 131, 1875-1878.

43. Engberink MF, Hendriksen MAH, Schouten EG et al. (2009) Inverse association between dairy intake and hypertension: the Rotterdam Study. Am J Clin Nutr 89, 1877-1883.

44. Appel LJ, Moore TJ, Obarzanek E et al. (1997) A clinical trial of the effects of dietary patterns on blood pressure. $N$ Engl J Med 336, 1117-1124.

45. Zemel MB (2009) Proposed role of calcium and dairy food components in weight management and metabolic health. Phys Sportsmed 37, 29-39.

46. Hypertension Detection and Follow-up Program Cooperative Group (1976) The hypertension detection and followup program. Prev Med 5, 207-215.

47. National Heart, Lung, and Blood Institute, Lipid Research Clinics Program, Laboratory Methods Committee (1974) Manual of Laboratory Operations: Lipid and Lipoprotein Analysis, 2nd ed. Bethesda, MD: US Department of Health and Human Services.

48. Friedewald WT, Levy RI \& Fredrickson DS (1972) Estimation of the concentration of low-density lipoprotein cholesterol in plasma, without use of the preparative ultracentrifuge. Clin Chem 18, 499-502.

49. Rose GA (1962) The diagnosis of ischaemic heart pain and intermittent claudication in field surveys. Bull World Health Organ 27, 645-658.

50. Smith TC, Wingard DL, Smith B et al. (2007) Walking decreased risk of cardiovascular disease mortality in older adults with diabetes. J Clin Epidemiol 60, 309-331.

51. Diabetes Drafting Group (1985) Prevalence of small vessel and large vessel disease in diabetic patients from 14 centres. The World Health Organisation Multinational Study of Vascular Disease in Diabetics. Diabetologia 28, Suppl., 615-640.

52. Gabir MM, Hanson RL, Dabelea D et al. (2000) The 1997 American Diabetes Association and 1999 World Health Organization criteria for hyperglycemia in the diagnosis and prediction of diabetes. Diabetes Care 23, 1108-1112.

53. Lockheart MS, Steffen LM, Rebnord HM et al. (2007) Dietary patterns, food groups and myocardial infarction: a casecontrol study. Br J Nutr 98, 380-387.

54. Tardy AL, Morio B, Chardigny JM et al. (2011) Ruminant and industrial sources of trans-fat and cardiovascular and diabetic diseases. Nutr Res Rev (Epublication ahead of print version)

55. Mozaffarian D, Cao H, King IB et al. (2010) Transpalmitoleic acid, metabolic risk factors, and new-onset diabetes in US adults: a cohort study. Ann Intern Med 153, 790-799.

56. Ferrara A, Barrett-Connor E \& Shan J (1997) Total, LDL, and HDL cholesterol decrease with age in older men and women. The Rancho Bernardo Study 1984-1994. Circulation 96, 37-43.

57. Criqui MH, Frankville DD, Barrett-Connor E et al. (1983) Change and correlates of change in high and low density lipoprotein cholesterol after six years: a prospective study. Am J Epidemiol 118, 52-59.

58. Freudenheim JL (1993) A review of study designs and methods of dietary assessment in nutritional epidemiology of chronic disease. J Nutr 123, 401-405. 